\title{
The Effects of a Healing Garden Program based on Vocational Adaptation on Career Attitude for College Students with Developmental Disabilities
}

\author{
Soo Yeon Kim* \\ Professor, Department of Rehabilitation Independence, Korea Nazarene university, Cheonan 456, Korea
}

\section{ABSTRACT}

The purpose of this study was to examine the effects of a healing garden program based on internal factors of vocational adaptation on career attitude for college students with developmental disabilities. First, healing garden program was defined by a group of experts related to education for developmental disabilities in the industry and academia through the focus group interview. Second, the healing garden program for college students with developmental disabilities was carried out for 15 weeks. Third, this study examined the effects of healing garden program based on internal factors of vocational adaptation on career attitude for college students with developmental disabilities. The participants of this study were 55 college students with developmental disabilities in N University, with 25 students placed in the experimental group and the other 30 in the control group. As a result of examination, the difference between before and after the program, it was found that factors of career attitude were improved significantly after the program in the experimental group, with Factor 1 (determination) increased from 2.08 to 3.39, Factor 2 (finality) from 2.28 to 3.19, Factor 3 (confidence) from 2.20 to 3.69 , Factor 4 (preparation) from 2.12 to 3.79, and Factor 5 (independence) from 1.88 to 3.63. But the control group did not show a significant improvement after 15 weeks of the program except Factor 3 (confidence) and Factor 5 (independence). It was found that the healing garden program based on internal factors of vocational adaptation had effects on career attitude for college students with developmental disabilities. Finally, the program will contribute to vocational rehabilitation for college students with disabilities. The findings further suggest that healing gardening programs that facilitate career attitudes must be continuously developed and applied in order to establish effective transition from school to the world of vocational adaptation.

Keywords: factor, rehabilitation, special education, therapy

\section{Introduction}

Since the Act on Special Education for Persons with Disabilities, Etc. amended in 2007, there have been more opportunities for persons with disabilities to enter college, which is an institution of higher education, and thus the number of college students with disabilities is constantly increasing (Kim, 2011). They have various reasons for entering college, but they lay stress on enhancing the com- petencies for employment and becoming financially independent. Thus, there is continuous need for research on expanding the scope of various jobs when running college curriculums related to vocational rehabilitation. In particular, persons with developmental disabilities among disability types tend to have low social adaptability due to lack of communication after employment, difficulty in building relationships, and lack of stress management skills (Shim, 2016). This is because persons with developmental

This Research was supported by the Korea Nazarene University Research Grants 2019.

Received: October 24, 2019, Revised: November 19, 2019, Accepted: January 11, 2020

First author: Soo Yeon Kim, ksy0713@kornu.ac.kr, (D) https://orcid.org/0000-0002-1130-454X

*Corresponding author: Soo Yeon Kim, ksy0713@kornu.ac.kr, (i) https://orcid.org/0000-0002-1130-454X 
disabilities have mental and physical damage before age 22 and face at least two or three functional restrictions in life such as self-protection, language, learning, mobility, capacity for independent living, and financial independence throughout the lifetime (Hong, 2012). Therefore, the field of vocational rehabilitation for developmental disabilities is seeking programs to overcome the problem of being psychologically intimidated by resolving the lack of living skills, which are a characteristic of developmental disabilities, and promoting the sense of achievement obtained through their jobs. Meanwhile, according to environmental psychologist Ulrich, healing gardens increase positive emotions, reduce negative emotions, prevent incidents that cause stress, and help produce the effect of enhancing attention (Lee et al., 2019; Ulrich, 1984). Therefore, based on the theoretical grounds about the strengths of healing gardens that contribute to stress reduction and psychological recovery in addition to emotional stability (Jung, 2002; Lee, 2016), this study sufficiently reviewed garden activities that can be done by college students with developmental disabilities in previous literature (Kim, 2016), and gave an operational definition of garden activities that are integrated with their employment competency after deliberation of an expert committee, and developed detailed programs. Moreover, this study structured healing garden programs based on vocational adaptation developed around this time that were comprised of activities related to vocational adaptation such as taking a walk and observing the surroundings, experiencing leisure in nature, collaborating through gardening, and communication gar- den-related vocational information, and analyzed whether the participants showed change in their career attitude. Here, career attitude refers to individual attitude, value system and expectancy toward the job he or show would get as well as the series of related activities (Kim, 2011). In other words, deciding and choosing one's career in life is one of the most important things in life, and thus career attitude is regarded as a significant value. Accordingly, this study sets the specific research question of whether the detailed components of career attitude such as determination, finality, confidence, preparation, and independence are changed by healing garden programs to verify the effects on change in career attitude, and determines the answer through an experiment. The ultimate goal of research is to contribute to the expansion of various therapeutic meanings to verify the applicability of healing gardens to vocational rehabilitation and integrate garden activities by presenting the effect of detailed factors on career attitude of college students with developmental disabilities as the objective data.

\section{Research Methods}

\section{Subjects}

This study was conducted on students in the undergraduate program specialized in developmental disabilities at $\mathrm{N}$ University in Cheonan, Chungnam, and the degree of disabilities is as shown in Table 1. The control group

Table 1. Characteristics of participants

\begin{tabular}{|c|c|c|c|c|}
\hline \multicolumn{2}{|c|}{ Group classification } & Type & Number & Percent $(\%)$ \\
\hline \multirow{7}{*}{$\begin{array}{l}\text { Experimental } \\
\text { group } \\
(n=25)\end{array}$} & \multirow{2}{*}{ Gender } & Male & 16 & 64 \\
\hline & & Female & 9 & 36 \\
\hline & \multirow{2}{*}{ Disability type } & Intellectual disability & 17 & 68 \\
\hline & & Autism & 8 & 32 \\
\hline & \multirow{3}{*}{ Disability grade } & Grade 1 & 0 & 0 \\
\hline & & Grade 2 & 4 & 16 \\
\hline & & Grade 3 & 21 & 84 \\
\hline \multirow{7}{*}{$\begin{array}{l}\text { Control } \\
\text { group } \\
(n=30)\end{array}$} & \multirow{2}{*}{ Gender } & Male & 21 & 70 \\
\hline & & Female & 9 & 30 \\
\hline & \multirow{2}{*}{ Disability type } & Intellectual disability & 23 & 77 \\
\hline & & Autism & 7 & 23 \\
\hline & \multirow{3}{*}{ Disability grade } & Grade 1 & 0 & 0 \\
\hline & & Grade 2 & 5 & 17 \\
\hline & & Grade 3 & 25 & 83 \\
\hline
\end{tabular}


had 21 male and nine female subjects (total 30), and the experimental group had 16 male and nine female subjects (total 25), adding up to total 55. By characteristics of disabilities, in the control group, 23 subjects have intellectual disability and seven have autism, and five have Grade 2 disability grading and 25 have Grade 3. In the experimental group, 17 subjects have intellectual disability and 8 have autism, and four have Grade 2 disability grading and 21 have Grade 3. The research was from March to June 2019, conducted by dividing the vocational adaptation class into two classes, structured the healing garden program based on vocational adaptation into five stages, and conducted the class for 15 weeks ( 3 hours per week) on both the experimental group that reflected the program on class and the control group that had regular vocational adaptation class. The venue for the experiment was the Able Center at $\mathrm{N}$ University as well as $\mathrm{S}$ botanical garden and $\mathrm{C}$ flower tea farm laboratory in Asan, Chungnam.

\section{Methods}

For persons with developmental disabilities, not only employment but also a stable social life through vocational adaptation is important (Kim, 2011). Therefore, for vocational adaptability to improve by experiencing various garden-related activities, this study reviewed previous studies (Kim, 2017; S.J. Lee et al., 2012) with reference to the job analysis of developmental disabilities by Kim (2018), and structured the healing garden programs by factor as shown in Table 2, with elements of vocational adaptation for college students with developmental disabilities applied through discussion of a committee of experts related to education for developmental disabilities (focus group interview). Here, those with a proper attitude toward vocations tend to show higher satisfaction with the job they choose (Kim, 1997), and thus can enjoy a productive life. From this perspective, this study reviewed the career attitude ele-

Table 2. The healing garden program based on vocational adaptation for college students with developmental disabilities

\begin{tabular}{|c|c|c|c|c|}
\hline $\begin{array}{c}\text { Vocational } \\
\text { adaptation factor }\end{array}$ & $\begin{array}{l}\text { Application of } \\
\text { main activity }\end{array}$ & Week & Application of sub activity & Expected effect \\
\hline $\begin{array}{l}\text { Factor } 1 \\
\text { (Self } \\
\text { determination } \\
\text { skill) }\end{array}$ & $\begin{array}{l}\text { Making own } \\
\text { choices based on } \\
\text { preferences and } \\
\text { advocating for } \\
\text { themselves }\end{array}$ & $\begin{array}{l}2 \\
3\end{array}$ & $\begin{array}{l}\text { Orientation } \\
\text { Introducing myself about career } \\
\text { Going out for a walk } \\
\text { Searching for favorite garden } \\
\& \text { drawing favorite home garden }\end{array}$ & $\begin{array}{l}\text {-Getting comfortable with career decision } \\
\text {-Perceiving own value or worth through self } \\
\text { introduction } \\
\text {-Increasing self determination skill and } \\
\text { self-expression by making own choices }\end{array}$ \\
\hline $\begin{array}{c}\text { Factor } 2 \\
\text { (Achievement) }\end{array}$ & $\begin{array}{l}\text { Enjoyment of } \\
\text { nature lifestyle } \\
\text { along with } \\
\text { financial stability }\end{array}$ & $\begin{array}{l}4 \\
5\end{array}$ & $\begin{array}{l}\text { Enjoying a kitchen garden } \\
\text { Making sprouts sandwich, pan fried } \\
\text { sweet rice, a cake with herbs } \\
\text { Walking and collecting wild flowers }\end{array}$ & $\begin{array}{l}\text {-Planning for a bright future } \\
\text {-Enjoying vegetables and flower tea } \\
\text {-Understanding herbs } \\
\text {-Understanding therapy garden }\end{array}$ \\
\hline $\begin{array}{c}\text { Factor } 3 \\
\text { (Job skill) }\end{array}$ & $\begin{array}{c}\text { Increasing } \\
\text { self-confidence } \\
\text { by caring plants }\end{array}$ & 9 & $\begin{array}{l}\text { Seed sowing project } \\
\text { Home gardening project }\end{array}$ & $\begin{array}{l}\text {-Increasing self-confidence through planting } \\
\text {-Increasing special gardening skill } \\
\text {-Interactions with the nature, happiness in caring it } \\
\text {-Observing various plants and having interests } \\
\text { and expectations about horticulture }\end{array}$ \\
\hline $\begin{array}{c}\text { Factor } 4 \\
\text { (Vocational } \\
\text { preparation skill) }\end{array}$ & $\begin{array}{l}\text { Field service } \\
\text { training }\end{array}$ & $\begin{array}{l}11 \\
12\end{array}$ & $\begin{array}{l}\text { Serving flower tea and fresh food } \\
\text { Cleaning flower shop \& cafe } \\
\text { Decorating flower cakes and } \\
\text { wrapping up }\end{array}$ & $\begin{array}{l}\text {-Field service training for career preparation } \\
\text {-Supporting others at work } \\
\text {-Following instructions at work } \\
\text {-Increasing self-expression and self-control through } \\
\text { strong adaption to the new job environment }\end{array}$ \\
\hline $\begin{array}{c}\text { Factor } 5 \\
\text { (Social skill) }\end{array}$ & $\begin{array}{l}\text { Social } \\
\text { interactions and } \\
\text { self-expression }\end{array}$ & $\begin{array}{l}13 \\
14 \\
15\end{array}$ & $\begin{array}{l}\text { Making job description manual } \\
\text { Networking, social interactions } \\
\text { Making portfolio about my garden } \\
\text { activity }\end{array}$ & $\begin{array}{l}\text {-Fulfilling professional performance with disability } \\
\text {-Increasing social support } \\
\text {-Training for self-expression and relieve stress } \\
\text {-Training for social interactions and self-expression } \\
\text {-Training for social networking }\end{array}$ \\
\hline
\end{tabular}




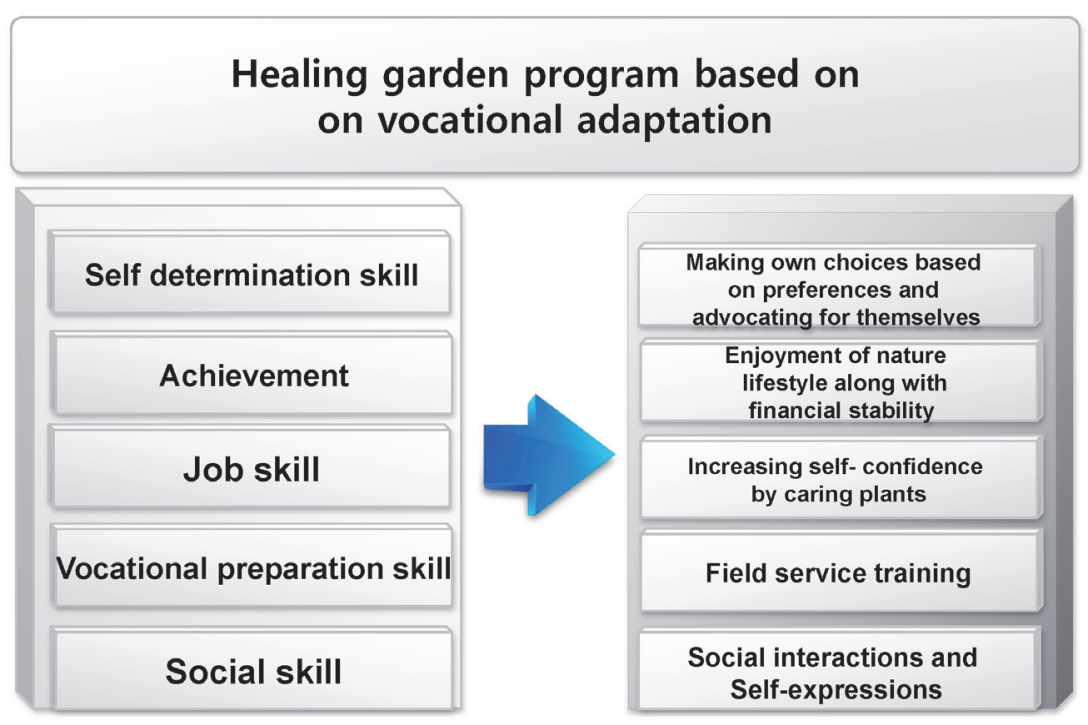

Fig. 1. Integrated contents of vocational adaptation in the healing garden program.

ments of Lee and Lee (2000) and vocational adaptation elements of Kim (2011). Factor 1 of vocational adaptation is self-determination skill in exploring and choosing garden-related information. Factor 2 is achievement, mainly about enjoying garden activities as leisure, and Factor 3 is confidence in job skill that includes taking care of and managing plants. Factor 4 is vocational preparation about experiencing gardening practice in the field, and Factor 5 is social skill such as communication and expression of garden activities and social network. Thus, this study came up with the structure of healing garden programs based on vocational adaptation with the factors above (Fig. 1). In the next stage, a detailed class is designed, specified based on vocational adaptation elements and the classification of garden activities for developmental disabilities by Kim (2018; Table 2). When discussed in the focus group interview, Factor 1 (self-determination skill) included activities such as exploring one's desirable garden in visual data, taking a walk while thinking of one's preferences and choosing them, and thus in the study by Rhyou (2002), persons with developmental disabilities can improve the ability to observe, think and decide on their own, which is necessary for those with developmental disabilities. Furthermore, it was designed for the participants to explain why they chose the garden, give presentations to others and express the ability to express their preferences. Factor 2 (achievement) was designed so that the participants, instead of thinking that stable vocational life is merely for financial purposes, financial independence will bring psychological stability and thus help them experience and enjoy relaxed life in nature such as drinking flower tea and cooking simple dishes as a leisure. Factor 3 (job skill) was designed for the participants to complete their job faithfully with confidence by taking care of and growing plants (S.J. Lee, 2007). Factor 4 (vocational preparation) was designed for the participants to have field experience to improve communication skills with others, comprised visiting the botanical garden and flower tea farm where they carried out activities such as cleaning up, displaying products and selling them to experience service. This also included the preparations for service. Factor 5 (social skill) was designed for the participants to determine their career on their own without depending on others, comprised of activities such as making a garden activity portfolio and organizing related data, associating it with job-seeking information and managing it, thereby improving social communication skills. Accordingly, the detailed programs of healing gardens were derived in combination with vocational adaptation (Table 2).

\section{Research tools}

To examine the current state of career attitude among college students with developmental disabilities, this study used the career attitude measurement tool developed by 
Table 3. Pre-experimental homogeneity test between groups

\begin{tabular}{cccccc}
\hline Factor & \multicolumn{3}{c}{ Mean (SD) } & \multirow{2}{*}{ t } & \multicolumn{1}{c}{$p$} \\
\cline { 2 - 3 } & Experimental & Control & & 1.329 & $.190^{\mathrm{NS}}$ \\
Determination & $2.08(0.572)$ & $1.91(0.387)$ & & .310 & $.758^{\mathrm{NS}}$ \\
Finality & $2.28(0.614)$ & $2.23(0.504)$ & & .355 & $.724^{\mathrm{NS}}$ \\
Confidence & $2.20(0.645)$ & $2.13(0.730)$ & & .791 & $.433^{\mathrm{NS}}$ \\
Preparation & $2.12(0.666)$ & $2.00(0.455)$ & & -.982 & $.330^{\mathrm{NS}}$ \\
Independence & $1.88(0.526)$ & $2.03(0.615)$ & & & \\
\hline
\end{tabular}

${ }^{\mathrm{NS}}$ Non-significant by independent t-test.

Lee and Han (1997). This was used as a tool by S.H. Lee et al. (2012) and H.Y. Lee (2007) in their study on career attitude of college students with disabilities, and thus its external validity is secured. This tool is comprised of 47 items in five subfields such as determination, finality, confidence, preparation and independence. The reliability coefficient (Cronbach's $\alpha$ ) of the career attitude measurement tool was .81, and it was rated on a 5-point Likert scale $(1=$ strongly disagree, $2=$ disagree, $3=$ neutral, $4=$ agree, 5 = strongly agree), with higher scores indicating higher maturity in career attitude. The questionnaire was comprised of total 51 items with three items in general characteristics such as gender, age and disability characteristics and 47 items related to career attitude. The details are as shown in Table 3.

\section{Data analysis}

This study measured career attitude of college students with developmental disabilities once before and once after the experiment. Data was analyzed using IBM SPSS Statistics 21.0, and normality was reviewed before the paired t-test on the mean difference between the experimental group and control group, analyzing the change in career attitude before and after the program. The homogeneity of the two groups was tested with an independent t-test.

\section{Limitations}

This study was conducted on 55 college students with developmental disabilities (intellectual disability, autism) attending the four-year $\mathrm{N}$ University in Chungcheongnam-do and thus is limited in generalizing the results to all college students with developmental disabilities with individualized characteristics.

This study had partial limitations as self-administered questionnaire since the instructor explained certain items that are difficult for college students with developmental disabilities to understand during the career attitude test.

\section{Results and Discussion}

\section{Test of homogeneity between groups before the program}

Among students in the specialized undergraduate department for developmental disabilities at $\mathrm{N}$ University, 25 students taking courses including the healing garden program based on vocational adaptation were included in the experimental group, and 30 students taking general courses on vocational adaptation based on theory were in the control group. Both groups are attending the specialized undergraduate department for developmental disabilities at $\mathrm{N}$ University and are preparing to get a job. A test of homogeneity was conducted between the two groups first to statistically compare career attitude according to participation. The results in Table 3 show that at $p<.05$ the two groups did not show a significant difference, and thus the homogeneity of the two groups was confirmed for the main survey.

\section{Pretest, posttest changes within the group}

To determine the effects on career attitude changes among college students with developmental disabilities, this study conducted a pretest and posttest on subfactors 
of career attitude, and the results are as follows. Prior to the analysis, the test of normality was conducted due to the small number of participants in the groups such as 25 in the experimental group and 30 in the control group. The result showed that both groups had normality as the Koimogorov-Smimov test showed the results of experimental group $p=.113$ and control group $p=.96$, and the ShapiroWilk test showed experimental group $p=.138$ and control group $p=.085$. Thus, a paired samples t-test was conducted. Table 4 shows the statistical analysis of career attitude factors such as determination, finality, confidence, preparation, and independence. Determination showed the posttest mean of 3.39 points in the experimental group, which is higher than the pretest mean of 2.08 points, showing statistically significant difference $(p<.05)$. However, in the control group, the posttest mean was 2.04 points, which was higher than the pretest mean of 1.91 points, but there was no statistically significant difference. Therefore, the healing garden program based on vocational adaptation for college students with developmental disabilities showed a significant improvement $\mathrm{n}$ determination. Here, determination is the ability to make decisions oneself, and the result also supports the report by Rhyou (2002) that persons with developmental disabilities lack the ability to make decisions on their own in forming career attitudes and thus acquiring self-determination skills is very important. In finality, the experimental group had the posttest mean of 3.19 points, which was much higher than the pretest mean of 2.28 points, and there was also a statistically significant difference. However, the control group had the posttest mean of 2.23 points and pretest mean of 2.22 points, not showing a significant difference. This indicates that finality is about having purpose for a behavior and thus clearly understanding the purpose of having a job. In other words, the purpose of college students with developmental disabilities in getting a job is related to enjoying leisure aside from achieving financial independence (Hong, 2012), and this result is proved by the healing garden program. Confidence refers to the assured feeling that one can solve his or her own problem, and thus increased confidence leads to improved ability to actively cope with vocational life. The experiment showed that the experimental group had the posttest mean of 3.69 points and the pretest mean of 2.20 points with significance $(p<.05)$. Moreover, the control group also showed the posttest mean of 2.52 points and the pretest mean of 2.13 points with significance. In other words, confidence was improved as the participants took care of plants during gardening activities based on vocational adaptation, but other vocational programs for developmental disabilities also affect confidence (Hong, 2012). Thus, when examining this result and reviewing the core competencies of vocational training at N University, confidence was set as the core competency, and thus it is not just an effect of the therapeutic garden. Preparation refers to the ability to collect information for employment or manage one's career. The experimental group had the

Table 4. Differences in career attitudes before and after the healing garden program based on vocational adaptation

\begin{tabular}{|c|c|c|c|c|c|c|c|}
\hline \multirow{2}{*}{ Indicator } & \multirow{2}{*}{ Group } & \multicolumn{2}{|c|}{ Before } & \multicolumn{2}{|c|}{ After } & \multirow{2}{*}{$\mathrm{t}$} & \multirow{2}{*}{$p$} \\
\hline & & $\mathrm{M}$ & SD & $\mathrm{M}$ & SD & & \\
\hline \multirow{2}{*}{ Determination } & Experimental & 2.08 & 0.572 & 3.39 & 0.641 & -8.563 & $<.001^{*}$ \\
\hline & Control & 1.91 & 0.387 & 2.04 & 0.721 & -1.270 & .214 \\
\hline \multirow{2}{*}{ Finality } & Experimental & 2.28 & 0.614 & 3.19 & 0.811 & -4.841 & $<.001^{*}$ \\
\hline & Control & 2.23 & 0.504 & 2.22 & 0.646 & -0.008 & .994 \\
\hline \multirow{2}{*}{ Confidence } & Experimental & 2.20 & 0.645 & 3.69 & 0.895 & -7.705 & $<.001^{*}$ \\
\hline & Control & 2.13 & 0.730 & 2.52 & 0.683 & -3.217 & $.003^{*}$ \\
\hline \multirow{2}{*}{ Preparation } & Experimental & 2.12 & 0.666 & 3.79 & 0.608 & -9.233 & $<.001^{*}$ \\
\hline & Control & 2.00 & 0.455 & 2.36 & 0.720 & -2.276 & .080 \\
\hline \multirow{2}{*}{ Independence } & Experimental & 1.88 & 0.526 & 3.63 & 0.800 & -8.480 & $<.001 *$ \\
\hline & Control & 2.03 & 0.615 & 2.93 & 0.742 & -4.927 & $<.001^{*}$ \\
\hline
\end{tabular}

${ }^{*} p<.05$ by paired t-test. 
posttest mean of 3.79 points, which was higher than the pretest mean of 2.12 points, and this showed a statistically significant difference $(p<.05)$. However, the control group did not show a significant difference, with the posttest mean of 2.36 points and the pretest mean of 2.00 points $(p<.05)$. This shows that, by conducting job-related class every week, the participants can explore and show interest in vocation and manage their career, and thus the healing garden program based on vocational adaptation that included visits and field placement at the botanical garden and flower tea farm significantly improved their realistic vocational preparation. This is also in line with the result of previous research that field placement based on job experience affects job performance (Kim, 2018). Moreover, as reported by previous research that independence is improved by various vocational experience programs in colleges that improve the dependent characteristics of persons with developmental disabilities (Hong, 2012), the experimental group showed the posttest mean of 3.63 points that was higher than the pretest mean of 1.88 points, and the control group also showed the posttest mean of 2.93 points and the pretest mean of 2.03 points, with a slight increase in the mean that shows statistically significant difference. Therefore, the effect of the healing garden program based on vocational adaptation on independence was significant in both groups. But even though vocational rehabilitation training for college students with developmental disabilities improves their independence, this is not just the effect of the healing garden program. Overall, when applying the healing garden program to a class associated with vocational adaptation, its effect on career attitude is significant in all factors such as determination, finality, confidence, preparation, and independence, but the effect on independence and confidence is not just the effect of the healing garden program. This is also supported by pervious studies that college students with developmental disabilities show a significant growth in confidence through most job-related programs (Kim, 2011; Hong, 2012). This is also in line with the result that many attempts and studies on career and vocation of persons with developmental disabilities help improve their self-management skills such as confidence and independence (Hwang, 2016). Nonetheless, the result that the healing garden program based on voca- tional adaptation has a positive effect on all components of career attitude for college students with developmental disabilities is in the same line as the study claiming that nature-based horticultural activities affect career attitude of multicultural women (Kwack and Jang, 2014). Thus, for people facing difficulty in social adaptation, garden-related programs have positive effects on their attitude toward realistic problems like getting a job by giving them activeness (S.J. Lee, 2007). In fact, according to the observation of the subjects, they showed greater interest in their career and higher expectancy for their leisure in garden activities, thereby becoming more active such as searching garden-related job information themselves or making a portfolio of their records in field placement. This proves that garden activities destroy the barriers in language or cultural knowledge and that they are accessible activities (Jung, 2002; Lee, 2016).

\section{Conclusion}

The healing garden program based on vocational adaptation developed to use in vocational training for developmental disabilities in college with vocational adaptation elements and garden activities is comprised of garden activities that affect career attitude changes by recovering mental and physical health with plants. This study designed and conducted a class that comprehensively structured the garden activities that can be linked to employment for college students with developmental disabilities and factors related to vocational adaptation such as self-determination skill, achievement, job skill, vocational preparation skill, and social skill. The results showed that the program developed in this study brought significant improvement to all of determination, finality, confidence, preparation, and independence for the experimental group when the two groups are homogeneous. On the other hand, the control group did not show significant results in determination, finality, and preparation, but showed significant results in confidence and independence. This indicates that both confidence and independence are mostly affected by vocational training for developmental disabilities in college. However, it can be found objectively that determination, finality, and 
preparation are significantly improved by the healing garden program. More specifically, the healing garden program based on vocational adaptation enables the participants to visually experience their favorite natural environment while taking a walk and positively improve self-determination skills through which they think and make decisions themselves. Furthermore, it was statistically proved that the program improves finality in which they understand the benefits of leisure and lifestyle that enjoys nature with psychological stability through jobs, rather than thinking jobs only as a financial purpose. Garden-related field placement based on collaboration also results in active career attitude that improves preparation for jobs by communicating job-related information effectively. In other words, vocational training for college students with developmental disabilities can have active and positive effects on improving career attitude by adopting it in the form of a healing garden program based on vocational adaptation that helps them heal their body and mind and experience various activities beyond just acquiring skills and techniques. Furthermore, it will contribute to continuous social integration with stable vocational adaptation even after employment.

\section{References}

Hong, J.K. 2012. The effects of job search program on career attitudes \& self-determination skills for college students with developmental disabilities. Master's thesis, Korea Nazarene university, Cheonan, Korea.

Hwang, Y.Y. 2016. A study on status and model of job creation project within each school. Doctoral dissertation, Korea Nazarene University, Cheonan, Korea.

Jung, H.J. 2002. Effect of horticultural therapy on the changes of self esteem and anxiety of the mentally retarded students in high school. Master's thesis, Konkuk University, Seoul, Korea.

Kim, B.W. 1997. Career decision level and career preparation behavior of the college students. Doctoral dissertation, Seoul National University, Seoul, Korea.

Kim, D.R. 2011. The effects of cultural english class based on internal factors of vocational adaptation on vocational readiness for college students with developmental disabilities. Doctoral dissertation, Dankook University, Seoul, Korea.

Kim, S.Y. 2016. Development of competency-based horticulture rehabilitation assistant curriculum for disability university students. J. Korean Soc. People Plants Environ. 19(6):595-604. https://doi.org/10.11628/ksppe.2016.19.6.595

Kim, S.Y. 2017. Effects of competency-based instructional design of indoor gardening course on job performance for university students with disabilities. J. People Plants Environ. 20(6):629-638. https://doi.org/10.11628/ksppe. 2017.20.6.629

Kim, S.Y. 2018. Development of competency-based horticulture rehabilitation assistant curriculum for developmental disability students. Master's thesis, Korea Nazarene University, Cheonan, Korea.

Kwack, H.R. and E.J. Jang. 2014. The effect of evocational education program based on horticultural activities on the self-efficacy, social adjustment, and guidance preparation action for married immigrant women. J. Korean Soc. People Plants Environ. 17(3):181-187. https://doi.org/10.11628/ksppe.2014.17.3.181

Lee, H.Y. 2007. A study on the factor analysis of a frequent change of occupation to persons with hearing impaired. Disabil. Employ. 17(1):141-164. https://doi.org/10.1570 7/disem.2007.17.1.005

Lee, J. 2016. Art therapy single case study of a patient with infant-adolescent cancer. Master's thesis. Ewha Womans University, Seoul. Korea.

Lee, K.H. and H.J. Lee. 2000. The effects of career self efficacy in predicting the level of career attitude maturity of college students. Korean J. Couns. Psychother. 12(1):127-136.

Lee, K.H. and J.C. Han. 1997. A validation study of the measurement tools for vocational attitude. J. Career Educ. Res. 8(1):219-255.

Lee, S.H., E.J. Song, and S.H. Lee. 2012. Review of core components of vocational education and support for successful employment of adolescents and adults with autism spectrum disorders. Korean J. Spec. Educ. 46(4):167-193.

Lee, S.J. 2007. Effect of horticultural therapy using the floral decoration training on the improvement of occupational performance ability and vocational rehabilitation in mentally retarded. Master's thesis, Konkuk University, Seoul, Korea. 
Lee, S.J., S.M. Lee, and J.K. Suh. 2012. The conceptual frame of horticultural therapy as vocational training (H.T.V.T.) for adolescents with intellectual disabilities. J. Korean Soc. People Plants Environ. 15(5):307-318.

Lee, S.M., N.R. Jeong, S.H. Jeong, G.M. Gim, K.S. Han, Y.Chea, K.J. Kim, and H.J. Jang. 2019. Consideration of programs and operations of farms providing agro-healing service. J. People Plants Environ. 22(1):1-14. https://doi.org10.11628/ksppe.2019.22.1.001

Rhyou, S.R. 2002. Development of a program for self determination activity and effects of the program on the level of self determination for students with mild disabilities in transition period. Doctoral dissertation, Ewha Women's University, Seoul, Korea.

Shim, W.I. 2016. A study on the level of satisfaction in the professional lives of the developmentally disabled participation in sporting activities. Master's thesis, Korea Nazarene university, Cheonan, Korea.

Ulrich, R.S. 1984. View through a window may influence recovery from surgery. Science 224:420-421.

https://doi.org/10.1126/science.6143402 